\title{
Hypotensive and Vasorelaxant Effects of Sericin-Derived Oligopeptides in Rats
}

\author{
Amnart Onsa-ard, ${ }^{1}$ Dawan Shimbhu, ${ }^{1}$ Jiraporn Tocharus, ${ }^{2}$ \\ Manote Sutheerawattananonda, ${ }^{3}$ Rungusa Pantan, ${ }^{4}$ and Chainarong Tocharus ${ }^{4}$ \\ ${ }^{1}$ Department of Biochemistry, Faculty of Medical Science, Naresuan University, Phitsanulok 65000, Thailand \\ ${ }^{2}$ Department of Physiology, Faculty of Medicine, Chiang Mai University, Chiang Mai 50200, Thailand \\ ${ }^{3}$ School of Food Technology, Institute of Agricultural Technology, Suranaree University of Technology, \\ Nakhon Ratchasima 30000, Thailand \\ ${ }^{4}$ Department of Anatomy, Faculty of Medicine, Chiang Mai University, Chiang Mai 50200, Thailand
}

Correspondence should be addressed to Chainarong Tocharus; chainarongt@hotmail.com

Received 30 August 2013; Accepted 22 September 2013

Academic Editors: R. Couture, S. Tsuruoka, and R. Villalobos-Molina

Copyright (C) 2013 Amnart Onsa-ard et al. This is an open access article distributed under the Creative Commons Attribution License, which permits unrestricted use, distribution, and reproduction in any medium, provided the original work is properly cited.

\begin{abstract}
Sericin-derived oligopeptides obtained from silk cocoons were investigated for the in vivo hypotensive effect and investigated for the underlying mechanism involved in vasodilation in isolated rat thoracic aorta. In normotensive anesthetized rats, oligopeptides induced an immediate and transient hypotensive activity. In rat aortic rings, oligopeptides induced a concentration-dependent vasorelaxation in vessels precontracted with both $\mathrm{KCl}$ and phenylephrine (PE) with endothelium-intact or endothelium-denuded rings. In endothelium-intact rings, pretreatment with $\mathrm{N} \omega$-Nitro-L-arginine methyl ester hydrochloride (L-NAME, $100 \mu \mathrm{M}$ ), an inhibitor of the NO synthase (NOS) or $1 \mathrm{H}$-[1,2,4] oxadiazolo[4,3-a]quinoxalin-1-one (ODQ, $1 \mu \mathrm{M})$, a selective inhibitor of the guanylyl cyclase enzyme, significantly reduced the relaxant effect of oligopeptides. However, indomethacin, an inhibitor of the cyclooxygenase, had no effect on oligopeptides-induced relaxation. In addition, pretreatment with tetraethylammonium (TEA, $5 \mathrm{mM}$ ) reduced the maximal relaxant effect induced by oligopeptides. By contrast, relaxation was not affected by 4 -aminopyridine (4-AP, $1 \mathrm{mM})$, glibenclamide $(10 \mu \mathrm{M})$, or barium chloride $\left(\mathrm{BaCl}_{2}, 1 \mathrm{mM}\right)$. In depolarization $\mathrm{Ca}^{2+}$-free solution, oligopeptides inhibited calcium chloride- $\left(\mathrm{CaCl}_{2}-\right)$ induced contraction in endothelium-denuded rings in a concentration-dependent manner. Nevertheless, oligopeptides attenuated transient contractions in $\mathrm{Ca}^{2+}$-free medium containing EGTA (1 mM) induced by $1 \mu \mathrm{M}$ PE, but they were not affected by $20 \mathrm{mM}$ caffeine. It is obvious that potent vasodilation effect of oligopeptides is mediated through both the endothelium and the vascular smooth muscle.
\end{abstract}

\section{Introduction}

Peptides derived from dietary proteins have been determined to modulate physiological functions. Bioactive peptides have also elicited antihypertensive and vasodilator functions [1]. The most common underlying mechanism of bioactive peptides has been studied in angiotensin-converting enzyme (ACE) inhibition [2-4]. Although the ACE inhibitor effects of bioactive peptides are most often studied, the vasorelaxant activity has also shown an important evidence for lowering blood pressure. It is well established that dietary protein found in soy protein [5], milk casein [6], and sweet potato [7] and its hydrolysates are capable of reducing blood pressure and modulating vascular activity. Recently, there are many reports that dietary-protein-derived peptides lower blood pressure and modulate vasodilation from several sources including egg white [8], soy protein [9], and $\kappa$-casein [10]. Moreover, silk fibroin, a core protein of silk fiber, has been shown to have potential hypotensive and antioxidant actions by fibroin hydrolysate [11]. Silk-fibroin-derived dipeptides, such as glycine-tyrosine, also produce an antihypertensive effect through angiotensin-converting enzyme (ACE) inhibition [12].

Sericin is a glue protein consisting of $20 \%-30 \%$ of the total cocoon weight which is synthesized in the middle gland 
of the Bombyx mori silkworm. Sericin is insoluble in cold water and is an indigestible intestinal protein. Sericin is composed of 18 amino acids and contains protein in a wide range of molecular weights from 10 to over $300 \mathrm{kDa}$ [13]. Sericin has shown numerous bioactivities, such as antioxidant [14], antitumor [15], antiproliferation [16], and anticholesterolemic properties [17]. Sericin can be degraded into peptides or hydrolysate forms. However, sericin and its hydrolysates have not been reported for vasorelaxation and blood pressure lowering. Therefore, in the present study, we investigated the possible mechanism involved in the blood pressure-lowering and vasomodulating effects of sericin-derived oligopeptides.

\section{Materials and Methods}

2.1. Preparation of Sericin-Derived Oligopeptides. Silk cocoons were autoclaved for $30 \mathrm{~min}$ to dissolve sericin protein. The sericin-rich protein solution was filtered through a cheese cloth to separate the extracted cocoons from the liquid part. The sericin solution obtained was subjected to enzymatic hydrolysis by protease (from Bacillus species, 16 unit/g, EC no. 2327522, Sigma, St. Louis, MO, USA). One $\mathrm{mL}$ of protease enzyme solution $(0.01 \mathrm{unit} / \mathrm{mL}$ protease enzyme in $0.036 \mathrm{M} \mathrm{CaCl}_{2}$ solution at a $1: 1$ volumetric ration) was added to $300 \mathrm{~mL}$ of the obtained sericin solution and incubated under shaking conditions at $37^{\circ} \mathrm{C}$ for $1 \mathrm{~h}$. The solution was then heated to $90^{\circ} \mathrm{C}$ for $15 \mathrm{~min}$ to stop the enzymatic activity and cooled to room temperature before centrifugation at $9500 \times \mathrm{g}$ for $15 \mathrm{~min}$ at $4^{\circ} \mathrm{C}$ to separate the solid portions. Oligopeptides with a molecular weight lower than $5 \mathrm{kDa}$ were separated from larger oligopeptides by ultra membrane filtration using a hollow fiber membrane with 5000 MWCO (molecular weight cutoff) (GE Healthcare Bio-Sciences AB, Uppsala, Sweden). The oligopeptides solution obtained was freeze-dried and kept in a sealed container at room temperature until use.

\subsection{Experimental Animals. Male Wistar rats (200-250 g)} were obtained from the National Laboratory Animal Center, Mahidol University, Salaya, Nakornpathom, Thailand. All animals were housed under a 12:12 h light-dark cycle conditions, with maintained temperature $\left(24 \pm 1^{\circ} \mathrm{C}\right)$. The animals were allowed free access to rodent diet and tap water. The experiment protocol was approved by the Animal Ethics Committee in accordance with the guide for the care and use of laboratory animals prepared by Chiang Mai University.

2.3. Blood Pressure in Anesthetized Normotensive Rats. The rats were anesthetized by intraperitoneal injection of sodium pentobarbital (50 mg/kg BW). The femoral artery was cannulated with polyethylene tubing 50 (Clay-Adams PE-50) filled with $100 \mathrm{IU}$ of heparin/mL connected to a pressure transducer to measure blood pressure. The blood pressure signal was amplified and converted to a digital signal by a bridge amplifier coupled with PowerLab (ADInstruments, Sydney, Australia). Systolic blood pressure (SBP), diastolic blood pressure (DBP), and heart rate (HR) were recorded with LabChart 7 software (ADInstruments, Sydney, Australia).
Oligopeptides were administered via a cannula inserted into the femoral vein with similar tubing to facilitate the intravenous injection of oligopeptides $(0.1 \mu \mathrm{g}-1000 \mu \mathrm{g} / \mathrm{kg} \mathrm{BW})$. Animals were allowed to equilibrate at least $20 \mathrm{~min}$ before the administration of any drugs [18]. Arterial pressure was allowed to return to the baseline level before the subsequent injections were conducted.

\subsection{Record of Isometric Vascular Tone}

2.4.1. Preparation of Isolated Rat Thoracic Aortic Ring. The rats were anesthetized by intraperitoneal injection of sodium pentobarbital (50 mg/kg BW). The thoracic aorta was immediately removed and cleaned from the connective tissues and fat. Aortic rings $(3-5 \mathrm{~mm})$ were obtained and immediately immersed into ice-cold Kreb's solution (composition in $\mathrm{mM}$ : $\mathrm{NaCl} 122 ; \mathrm{KCl} \mathrm{5}$; (HEPES) 10; $\mathrm{KH}_{2} \mathrm{PO}_{4} 0.5 ; \mathrm{NaH}_{2} \mathrm{PO}_{4} 0.5$; $\mathrm{MgCl}_{2} 1$; glucose $11 ; \mathrm{CaCl}_{2}$ 1.8; $\mathrm{pH}$ 7.4) until use. The endothelium-denuded rings were obtained by mechanically removing the endothelial layer by gentle rubbing around the internal vascular surface [19]. The aortic rings were mounted between a pair of platinum wires in an organ bath containing Krebs' solution, maintained at $37^{\circ} \mathrm{C}$ and continuously bubbled with air. A resting tension of 1 gram was applied to each tissue and allowed to equilibrate at least $1 \mathrm{~h}$. The endothelium integrity was verified by relaxation to Ach $(1 \mu \mathrm{M})$ in rings precontracted by $\mathrm{PE}(1 \mu \mathrm{M})$. The vascular endothelium was considered intact when aortic rings were relaxed $90 \%$ of the PE-induced precontractions, whereas the endothelium-denuded ring was confirmed with an absence of vasorelaxation. Changes in isometric tension were recorded and analyzed through a force transducer (Iworx Systems, Inc., $\mathrm{NH}$, USA), coupled with bridge amplifier (ADInstruments, Sydney, Australia), PowerLab (ADInstruments, Sydney, Australia), and signal virtualization by Labchart 7 software (ADInstruments, Sydney, Australia).

2.4.2. Effect of Oligopeptides on Contractions Induced by PE and $\mathrm{K}^{+}$. Vasorelaxant effects of oligopeptides were investigated in both endothelium-intact and endothelium-denuded aortic rings. After the ring was preequilibrated, the aortic ring was precontracted with $\mathrm{PE}(1 \mu \mathrm{M})$ or $\mathrm{KCl}(80 \mathrm{mM})$ until the stability of tension was developed and followed by cumulative exposure to oligopeptides at the concentration of 0.001-10 $\mathrm{mg} / \mathrm{mL}$. The extent of relaxation was expressed as the percentage of $\mathrm{PE}$ - or $\mathrm{KCl}$-induced contraction.

2.4.3. Role of Endothelium-Derived Mediators in the Relaxant Effect of Oligopeptides. To investigate the mechanism responsible for oligopeptides-induced vasorelaxation, the endothelium-intact rings were precontracted with $\mathrm{PE}(1 \mu \mathrm{M})$ for $30 \mathrm{~min}$ after being exposed to either L-NAME $(100 \mu \mathrm{M})$, an inhibitor of the NO synthase (NOS), indomethacin $(10 \mu \mathrm{M})$, an inhibitor of the cyclooxygenase (COX), or LNAME plus indomethacin. And, then, vasorelaxation was carried out by the cumulative exposure to oligopeptides at the concentrations of $0.001-10 \mathrm{mg} / \mathrm{mL}$. 
2.4.4. Role of $\mathrm{K}^{+}$Channels Involvement in OligopeptidesInduced Vasorelaxation. To examine the role of $\mathrm{K}^{+}$channels involvement in vasorelaxation, the endothelium-denuded ring was used for this determination by preincubation with one of the following $\mathrm{K}^{+}$channel blockers: tetraethylammonium, a nonselective inhibitor of $\mathrm{K}^{+}$channels (TEA, $5 \mathrm{mM}$ ), 4-aminopyridine, an inhibitor of voltage-operated $\mathrm{K}^{+}$channel (4-AP, $1 \mathrm{mM}$ ), glibenclamide, an inhibitor of $\mathrm{K}^{+}$ channels activated by adenosine triphosphate $(10 \mu \mathrm{M})$, and $\mathrm{BaCl}_{2}(1 \mathrm{mM})$ for $30 \mathrm{~min}$ before PE $(1 \mu \mathrm{M})$ precontraction. Then, the cumulative concentration response of oligopeptides at the concentrations of $0.001-10 \mathrm{mg} / \mathrm{mL}$ was directly added.

\subsubsection{Role of Soluble Guanylyl Cyclase (sGC) in Oligopeptides-} Induced Vasorelaxation. To evaluate whether oligopeptides possessed vasorelaxation via the sGC activation, the endothelium-intact ring was incubated with $1 \mathrm{H}$ $[1,2,3]$ oxadiazolo[4,3- $\alpha]$ quinoxalin-1-one, a selective inhibitor of the guanylyl cyclase enzyme (ODQ, $1 \mu \mathrm{M}$ ) for $30 \mathrm{~min}$ before contraction with $\mathrm{PE}(1 \mu \mathrm{M})$ treatment. Oligopeptides at the concentrations of $0.001-10 \mathrm{mg} / \mathrm{mL}$ were cumulatively added. The ability of vasorelaxation was compared in absence (control) and presence of ODQ.

\subsubsection{Effect of Oligopeptides on Extracellular $\mathrm{Ca}^{2+}$ Influx to} $S M C$. To investigate the effects of oligopeptides on $\mathrm{Ca}^{2+}$ channel, the endothelium-denuded aortic ring was placed under $\mathrm{Ca}^{2+}$-free Krebs' solution for $20 \mathrm{~min}$ and then exposed for an additional $10 \mathrm{~min}$ to $\mathrm{K}^{+}(80 \mathrm{mM}), \mathrm{Ca}^{2+}$-free solution for complete smooth muscle cell depolarization to open a voltage-operated $\mathrm{Ca}^{2+}$ channel (VOCC). The cumulative concentration-response curve of $\mathrm{CaCl}_{2}$ (ranging from $10 \mu \mathrm{M}$ to $10 \mathrm{mM}$ ) was obtained. After the maximal response was performed, the rings were washed out and replaced with $\mathrm{Ca}^{2+}$-free solution for $20 \mathrm{~min}$. The $\mathrm{Ca}^{2+}$-free $80 \mathrm{mM} \mathrm{K}^{+}$was reexposed to flowing with preincubation of either oligopeptides $(1,3,5$, and $10 \mathrm{mg} / \mathrm{mL})$ or nifedipine, L-type $\mathrm{Ca}^{2+}$ channel blocker $(1 \mu \mathrm{M})$ for $20 \mathrm{~min}$. The maximal contraction obtained with the control concentration response curve to $\mathrm{CaCl}_{2}$ was taken as $100 \%$, and all values were calculated as a percentage of the maximal response.

\subsubsection{Effect of Oligopeptides on $\mathrm{Ca}^{2+}$ Release from Intracellular} Stores Sensitive to PE and Caffeine. To investigate the effect of oligopeptides on PE- or caffeine-sensitive intracellular calcium stores, endothelium-denuded rings were bathed in $\mathrm{Ca}^{2+}$-free Kreb's solution containing $1 \mathrm{mM}$ EGTA after incubation with $80 \mathrm{mM} \mathrm{KCl}$ for successful $\mathrm{Ca}^{2+}$ loading into SR. The transient contractions were obtained in aortic rings by $\mathrm{PE}(1 \mu \mathrm{M})$ or caffeine $(20 \mathrm{mM})$ in $\mathrm{Ca}^{2+}$-free solution before and after being incubated with oligopeptides $(1,5$, and $10 \mathrm{mg} / \mathrm{mL}$ ). The results were expressed as percentage of the response induced by $\mathrm{PE}$ or caffeine alone.

2.5. Statistical Analysis. All data were expressed as mean \pm SEM. Statistical analysis was performed using Student's $t$ test or one-way analysis of variance (ANOVA) followed by
Tukey's post hoc test. The $P<0.05$ was considered to be significant. Concentration-response curves were plotted, and experimental data were obtained by using nonlinear curves fit program (GraphPad Prism 5).

\section{Results}

3.1. Hypotensive Effect of Oligopeptides in Normotensive Anesthetized Rats. We investigated the effect of oligopeptides on blood pressure in normotensive rats. The baselines of SBP, DBP, and HR were $122.8 \pm 1.64 \mathrm{mmHg}, 107 \pm 3.74 \mathrm{mmHg}$, and $366 \pm 2.67 \mathrm{BPM}$, respectively. Intravenous administration of oligopeptides dose dependently decreased SBP and DBP in rats (Figures 1(a) and 1(b)). The hypotensive response in each dose of oligopeptides was completely recovered to the baseline within a few minutes. In addition, oligopeptides at all doses did not show any obvious effect on HR (Figure 1(c)).

3.2. Effect of Oligopeptides on Contraction Induced by PE and $\mathrm{KCl}$. Oligopeptides significantly relaxed $\mathrm{PE}$ - and $80 \mathrm{mM}$ $\mathrm{KCl}$-precontracted aortic rings in a concentration-dependent manner. However, oligopeptides completely relaxed in PE$\left(E_{\max }=95.46 \pm 1.86 \%\right)$ induced contractions in the aortic rings and partially relaxed in $\mathrm{KCl}-\left(80 \mathrm{mM}, E_{\max }=\right.$ $55.22 \pm 7.56 \%$ ) induced contractions (Figures 2(a) and 2(b)). The endothelium-denuded ring significantly decreased the vasodilator effects only on the $\mathrm{PE}$ precontraction (Figure 2(a)), while, for $80 \mathrm{mM} \mathrm{KCl}$, precontraction had no effects (Figure 2(b)).

3.3. Role of Nitric Oxide (NO) and Prostanoids in Oligopeptides-Induced Vasorelaxation. NO and prostacyclin are known to be vasorelaxing mediators derived from endothelium. In endothelium-intact preparation, oligopeptides relaxed the PE- $(1 \mu \mathrm{M})$ induced contractions with an $\mathrm{EC}_{50}$ value of $1.86 \pm 0.16 \mathrm{mg} / \mathrm{mL}$ (Figure 3 ). In the presence of L-NAME and L-NAME plus indomethacin, the relaxant effect of oligopeptides against PE- $(1 \mu \mathrm{M})$ induced contraction was markedly attenuated with an $\mathrm{EC}_{50}$ value of $13.49 \pm 0.18$ and $8.71 \pm 0.15 \mathrm{mg} / \mathrm{mL}$, respectively (Figure 3). By contrast, treatment of the aortic ring with indomethacin showed no modification in endothelium-intact rings (Figure 3).

3.4. Role of $\mathrm{K}^{+}$Channel in Oligopeptides-Induced Vasorelaxation. To verify the role of $\mathrm{K}^{+}$channel in oligopeptides-induced vasorelaxation, the endotheliumdenuded ring was preincubated with different potassium channel inhibitors: tetraethylammonium $(5 \mathrm{mM})$, 4aminopyridine $(1 \mathrm{mM})$, glibenclamide $(10 \mu \mathrm{M})$, or $\mathrm{BaCl}_{2}$ $(1 \mathrm{mM})$ before the ring was contracted with PE. All inhibitors did not alter the concentration-response curve for oligopeptides as shown in Figures 4(a) and 4(b). However, the maximal relaxant activity of oligopeptides which were preincubated with tetraethylammonium was markedly reduced $\left(E_{\max }=54.82 \pm 2.63 \%\right)$ compared to the control $\left(E_{\max }=83.74 \pm 5.61 \%\right)$. 


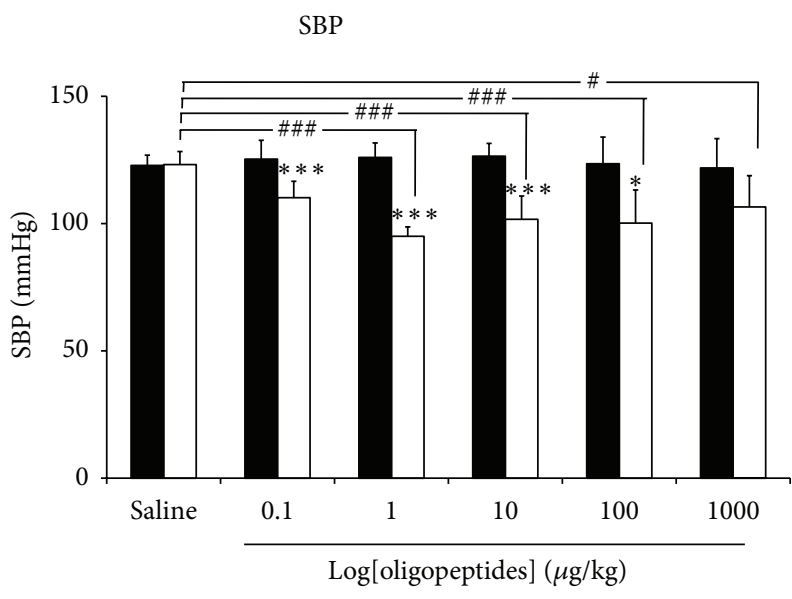

- Before injection

a After injection

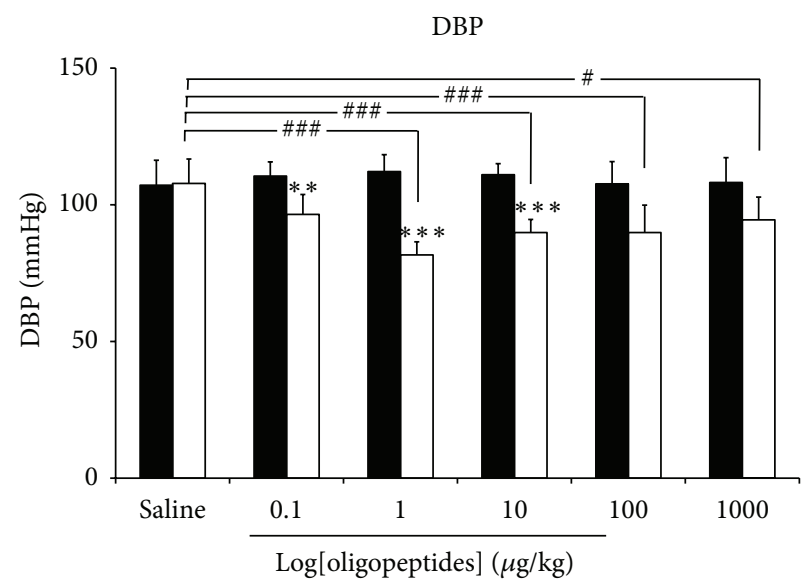

- Before injection

口 After injection

(a)

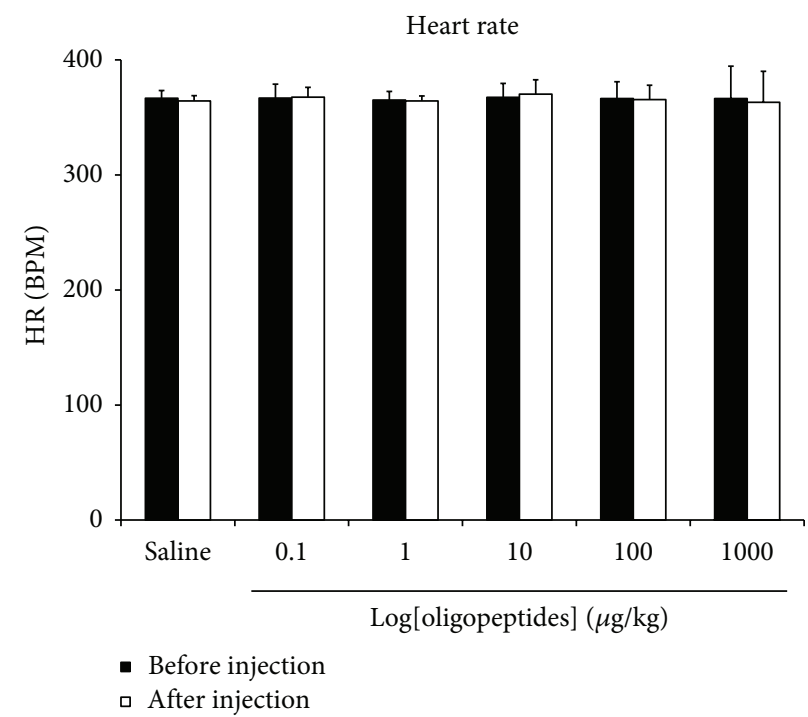

(c)

FIGURE 1: The maximal reduction of (a) systolic blood pressure, (b) diastolic blood pressure, and (c) heart rate caused by intravenous administration of oligopeptides $(1-1000 \mu \mathrm{g} / \mathrm{kg} \mathrm{BW})$ in normotensive rats. The results are expressed as mean \pm SEM; $n=6$; ${ }^{*} P<0.05$; ${ }^{* *} P<0.01$; and ${ }^{* * *} P<0.001$ compared with before injection. ${ }^{\#} P<0.05$, and ${ }^{\# \# \#} P<0.001$ compared with saline injection.

3.5. Role of $s G C$ in Oligopeptides-Induced Vasorelaxation. ODQ $(1 \mu \mathrm{M})$ significantly abolished the oligopeptidesinduced vasorelaxation in the endothelium-intact ring (Figure 5). It markedly decreased both the potency $\left(\mathrm{EC}_{50}=11.22 \pm 0.91 \mathrm{mg} / \mathrm{mL}\right)$ and maximal relaxation $\left(E_{\max }=12.09 \pm 4.63 \%\right)$ when compared to untreated control values $\left(\mathrm{EC}_{50} 1.86 \pm 0.79 \mathrm{mg} / \mathrm{mL}\right.$, and $\left.E_{\max }=95.03 \pm 1.86 \%\right)$.

3.6. Effects of Oligopeptides on $\mathrm{CaCl}_{2}$-Induced Contractions. The concentration-response curves of $\mathrm{CaCl}_{2}(10 \mu \mathrm{M}-10 \mathrm{mM})$ were performed in the $80 \mathrm{mM} \mathrm{KCl} \mathrm{Ca}^{2+}$-free solution. The percentage of maximal response $\left(E_{\max }\right)$ of $\mathrm{CaCl}_{2}$ alone $(100 \%)$ was attenuated in the presence of oligopeptides $(1,3,5$, and $10 \mathrm{mg} / \mathrm{mL})$ in a concentration-dependent manner $(83.02 \pm$ $6.78 \%, 54.00 \pm 1.98 \%, 39.52 \pm 2.28 \%$, and $31.61 \pm 2.6 \%$, resp.), while $\mathrm{EC}_{50}$ values were similar (Figure 6). In addition, nifedipine $(1 \mu \mathrm{M})$ also abolished the contraction of $\mathrm{CaCl}_{2}$. This suggested that $\mathrm{Ca}^{2+}$ influx was probably reduced by oligopeptides.

3.7. Effect of Oligopeptides on the SR $\mathrm{Ca}^{2+}$ Release to PE and Caffeine Activation. Preincubation of endothelium-denuded rings with oligopeptides at the concentrations of 1,5 , and $10 \mathrm{mg} / \mathrm{mL}$ dose dependently decreased the transient contractions induced by $\mathrm{PE}(10 \mu \mathrm{M})$ in $\mathrm{Ca}^{2+}$-free Krebs' solution containing EGTA $(1 \mathrm{mM})$ (Figure $7(\mathrm{a})$ ). By contrast, oligopeptides produced no significant effect on the transient contractions induced by caffeine $(20 \mathrm{mM})$ in a similar condition (Figure 7(b)). 


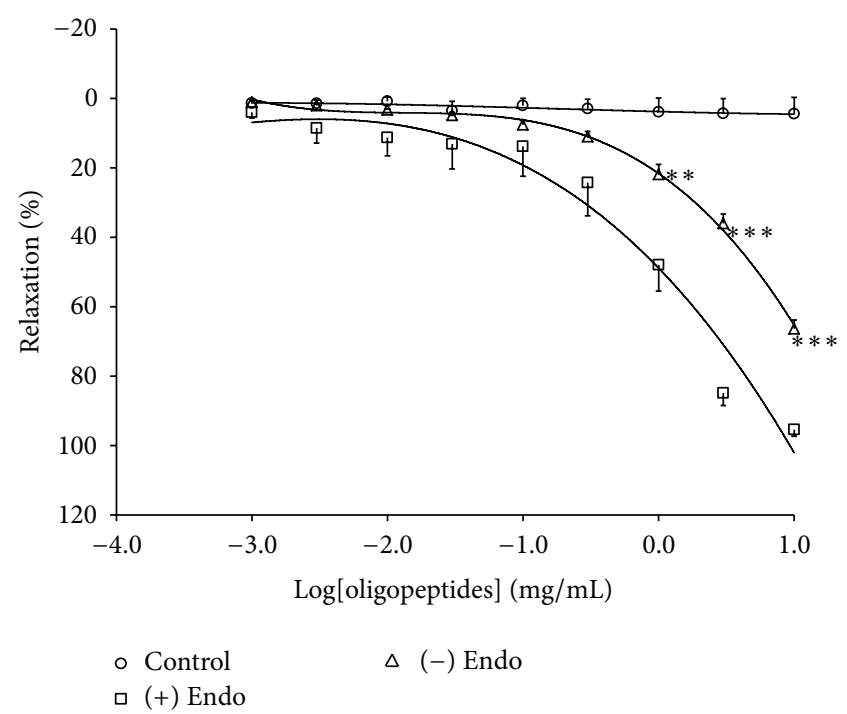

(a)

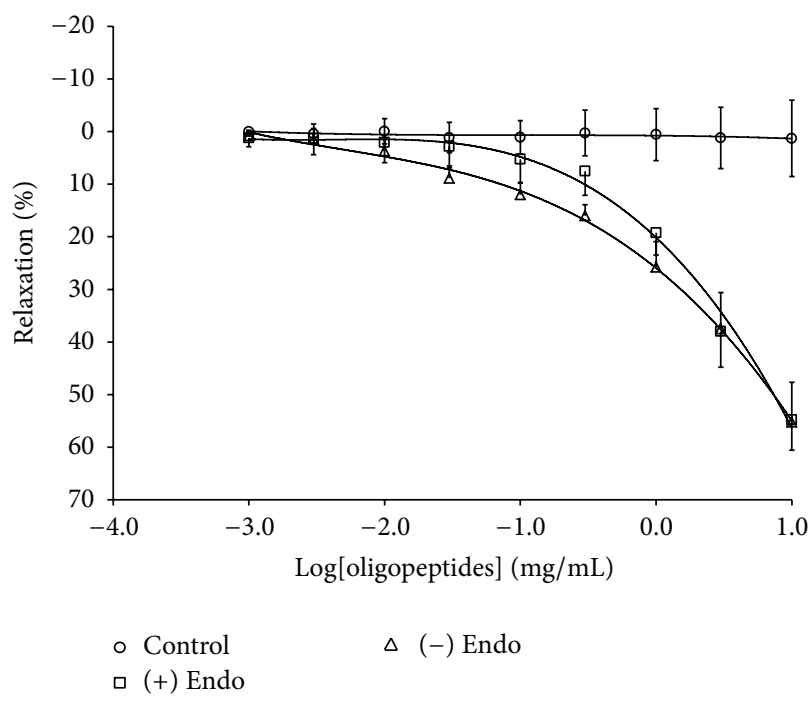

(b)

FIGURE 2: Vasorelaxant effects of oligopeptides on the contraction induced by $\mathrm{PE} \mathrm{(a)} \mathrm{and} 80 \mathrm{mM} \mathrm{KCl} \mathrm{(b)} \mathrm{in} \mathrm{endothelium-intact} \mathrm{and} \mathrm{-denuded}$ aortic rings. The results are expressed as mean \pm SEM; $n=6 ;{ }^{* *} P<0.01$; and ${ }^{* * *} P<0.001$ compared with endothelium-intact rings. + Endo $=$ endothelium-intact rings, and - Endo $=$ endothelium-denuded rings.

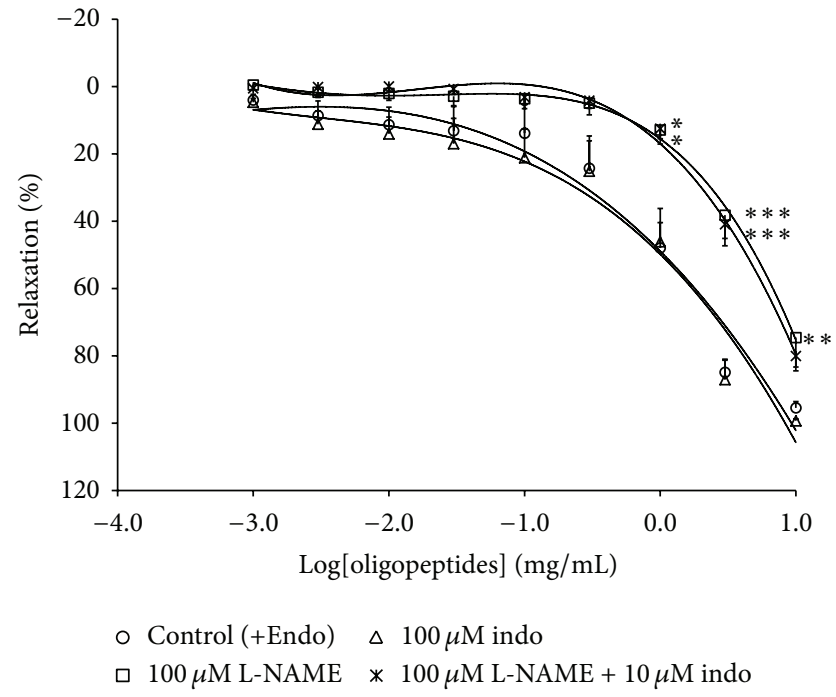

FIGURE 3: Concentration-response curve of oligopeptides on vasorelaxation modulated by L-NAME $(100 \mu \mathrm{M}, n=6)$, Indo $(10 \mu \mathrm{M}$, $n=8)$, and combination of L-NAME and Indo $(n=6)$ in PE$(1 \mu \mathrm{M})$ precontracted aortic rings with endothelium. The results are presented as mean \pm SEM; ${ }^{*} P<0.05 ;{ }^{* *} P<0.01$; and ${ }^{* * *} P<0.001$ compared with control.

\section{Discussion}

Sericin is a protein derived from the silk cocoon that appears as waste in silk processing. Sericin is a mixture of polypeptides of molecular mass varying between 10 and $300 \mathrm{kDa}$ [13] and has high serine contents (30\%-33\%). In the past decade, various biological activities regarding sericin have been reported in gastric injuries [14] and protection against tumorigenesis [15], antioxidation, inhibition of tyrosinase [20], alcohol-induced liver [21], and UV-induced keratinocyte apoptosis [22]. In the present study, sericin was hydrolyzed, and it generated the bioactive peptides with lowmolecular- $(5 \leq \mathrm{kDa})$ sized peptides. The sericin-derived oligopeptides exerted vasorelaxant activities in rats, which explain their hypotensive effects. We found that oligopeptides lowered blood pressure in normotensive rats. The reduction of blood pressure was transient, and it recovered to baseline level in a few minutes by dose-dependent intravenous administration of oligopeptides. Although the reduction of blood pressure occurred, the level of blood pressure was still within normotensive limits, whereas heart rate was unaffected. We further investigated the possible vasodilator effects of oligopeptides in the isolated rat aorta. Oligopeptides induced a concentration-dependent vasorelaxation on PE-induced precontractions in endothelium-intact and -denuded aortic rings, and this relaxation was attenuated by endothelium denudation. These results suggested that oligopeptides acted to cause vasorelaxation in endothelium-dependent aortic rings. The vascular endothelial cells pivotally acted in vascular homeostasis by modulating the vascular smooth muscle tone [23]. Thus, indomethacin, a cyclooxygenase inhibitor, and L-NAME, an inhibitor of NO synthase, were employed to investigate the involvement of prostacyclin and NO in vasodilation effect [24]. The results showed that oligopeptidesinduced vasorelaxation was markedly suppressed by LNAME, but not by indomethacin, suggesting the participation of $\mathrm{NO}$ in the vasorelaxation effect of oligopeptides. Furthermore, L-NAME plus indomethacin revealed no further inhibition than that observed with L-NAME alone. This showed that NO is a powerful relaxant mediator involvement in oligopeptides-induced vasorelaxation.

It is well known that the $\mathrm{NO} / \mathrm{sGC}$ pathway is one of the most common potential mechanisms that induce 


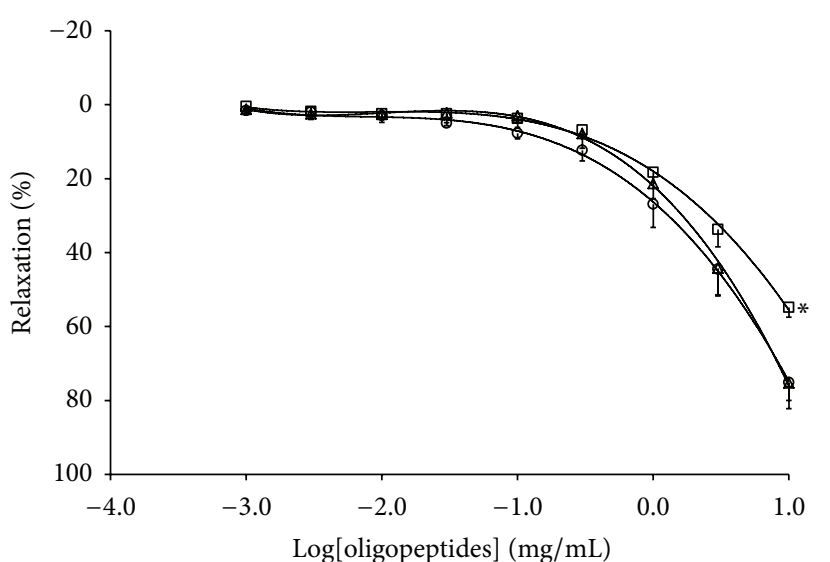

$\circ$ Control (-Endo) $\quad \Delta \mathrm{BaCl}_{2}$
$\square$ TEA

(a)

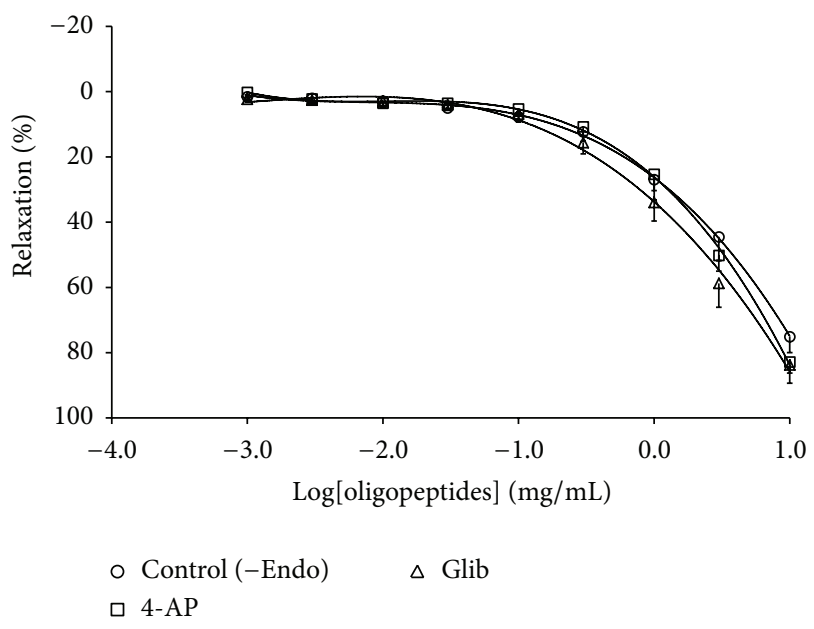

(b)

FIGURE 4: Effects of inhibitor of $\mathrm{K}^{+}$channels on vasorelaxant response induced by oligopeptides on endothelium-denuded aortic rings precontracted with PE $(1 \mu \mathrm{M})$ in presence of (a) TEA $(5 \mathrm{mM}, n=7)$ and $\mathrm{BaCl}_{2}(1 \mathrm{mM}, n=6)$ and (b) 4 -AP $(1 \mathrm{mM}, n=7)$ and Glib (10 $\mu \mathrm{M}$, $n=6)$. The data are expressed as mean $\pm \mathrm{SEM},{ }^{*} P<0.05$, compared with control (-Endo).

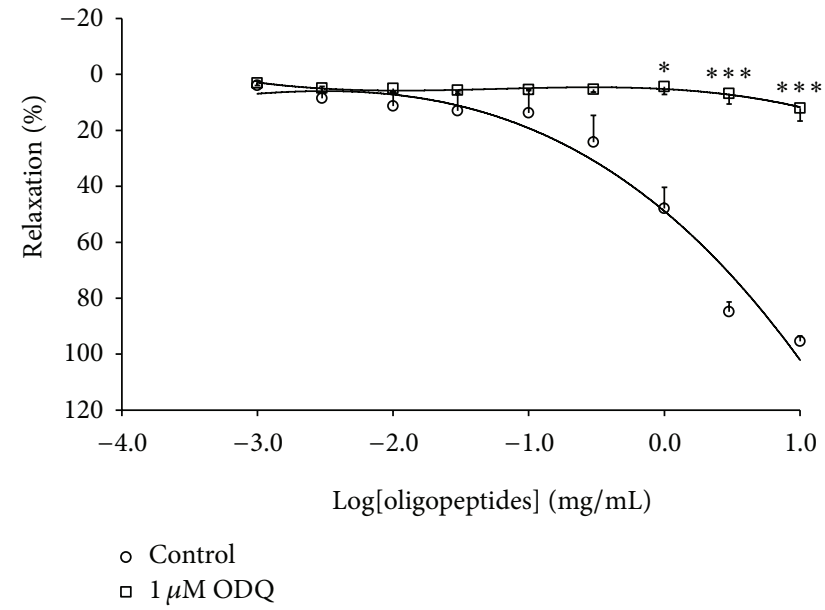

FIGURE 5: Vasorelaxant response of oligopeptides on rat aortic rings precontracted by PE $(1 \mu \mathrm{M})$ in presence of ODQ $(1 \mu \mathrm{M}, n=6)$. Results are presented as mean $\pm \mathrm{SEM} ; n=6 ;{ }^{*} P<0.05 ;{ }^{* * *} P<0.001$ compared with control.

vascular smooth muscle relaxation through activation of guanylyl cyclase, leading to the accumulation of cyclic GMP that inhibits $\mathrm{Ca}^{2+}$ influx. ODQ, a soluble guanyly cyclase inhibitor, was used to confirm the relationship of the vasorelaxant response of oligopeptides. This finding showed the significant inhibitory effects of ODQ in oligopeptidesinduced endothelium-dependent vasorelaxation, which confirmed that the vasorelaxation of the aorta elicited by oligopeptides was mediated in the endothelium-dependent $\mathrm{NO} / \mathrm{sGC} / \mathrm{cGMP}$ pathway. However, the vasorelaxation effect of oligopeptides was still observed in aortic endotheliumdenuded rings, suggesting that oligopeptides have a direct

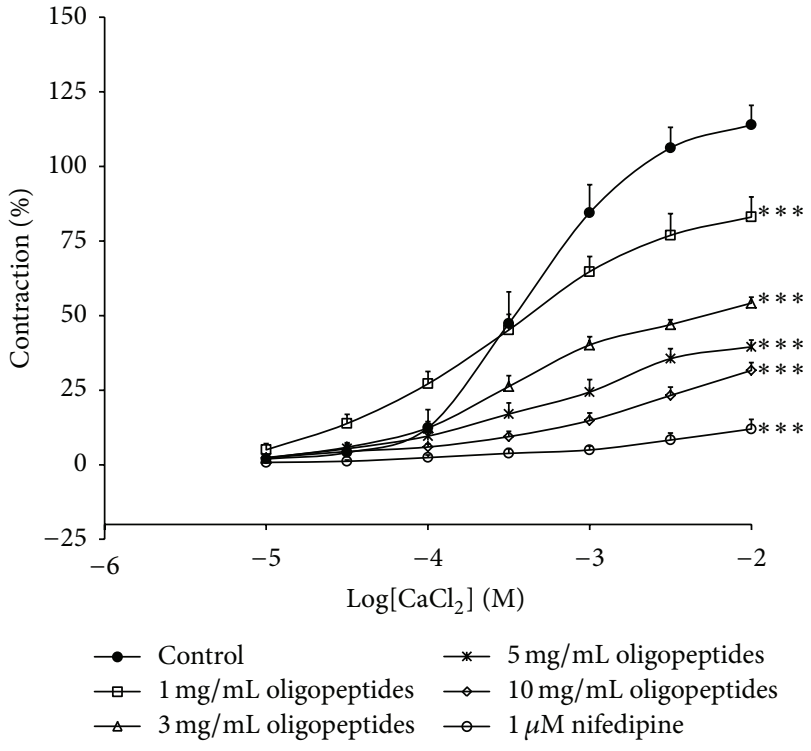

FIGURE 6: Inhibitory effects of oligopeptides $(1,3,5$, and $10 \mathrm{mg} / \mathrm{mL})$ or nifedipine $(1 \mu \mathrm{M})$ on the concentration-response curve for $\mathrm{CaCl}_{2}$ induced contraction in $\mathrm{Ca}^{2+}$-free $80 \mathrm{mM} \mathrm{KCl}$ solution. Results are expressed as mean \pm SEM; $n=6 ;{ }^{*} P<0.05 ;{ }^{* *} P<0.01$; and ${ }^{* * *} P<$ 0.001 compared with control.

effect on vascular smooth muscle cells. The opening of $\mathrm{K}^{+}$ channels or $\mathrm{Ca}^{2+}$ channel blocker in the vascular smooth muscle cells provides an important mechanism to dilate arteries. We further investigated the mechanisms of vasorelaxation that are independent of the endothelium. The vasorelaxant effect of oligopeptides was partially inhibited by the TEA $\left(\mathrm{Ca}^{2+}\right.$-activated $\mathrm{K}^{+}$channel blocker). Other $\mathrm{K}^{+}$blockers, 


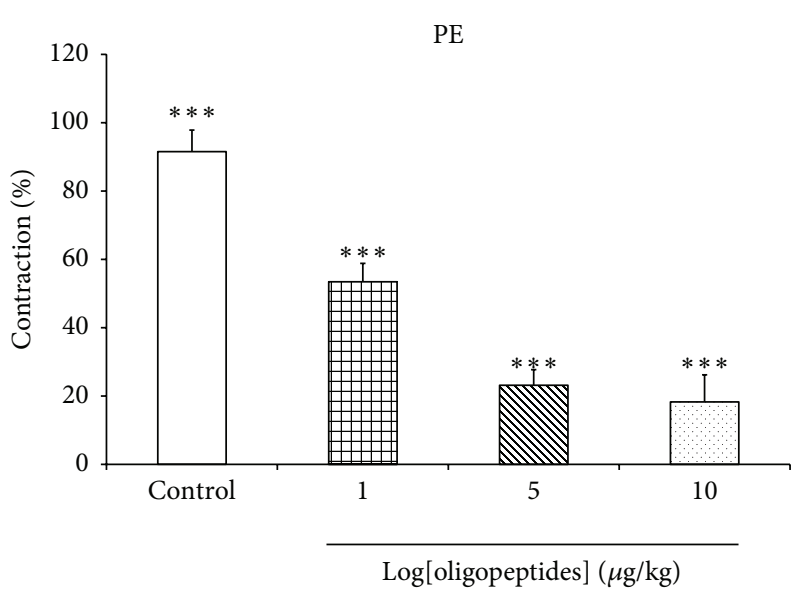

(a)

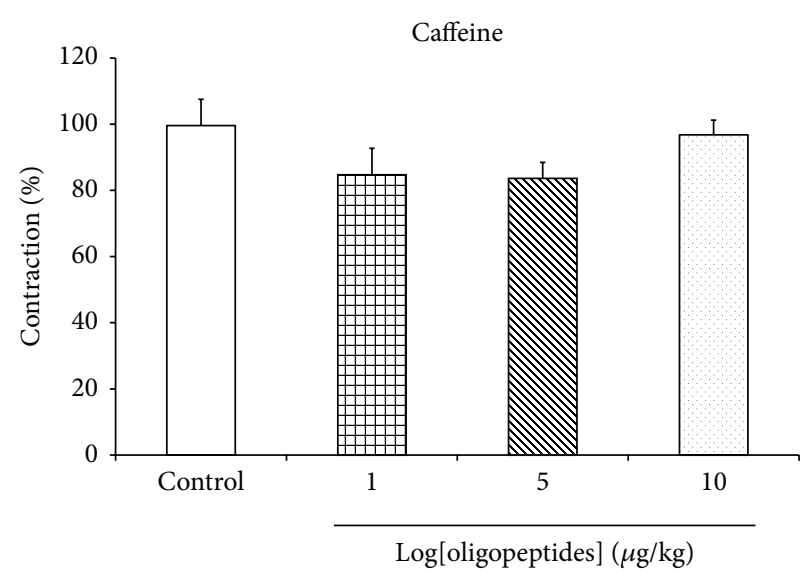

(b)

Figure 7: The effects of oligopeptides $(1,5$, and $10 \mathrm{mg} / \mathrm{mL})$ inhibited $\mathrm{Ca}^{2+}$ release from the SR by (a) PE $(1 \mu \mathrm{M})$ and (b) caffeine (20 mM) in isolated aortic rings without endothelium. Results are expressed as mean \pm SEM; $n=6 ;{ }^{* * *} P<0.001$ compared with control.

glibenclamide (ATP-sensitive $\mathrm{K}^{+}$channel blocker), 4-AP (voltage-activated $\mathrm{K}^{+}$channel blocker), and $\mathrm{BaCl}_{2}$ (inwardly rectifying $\mathrm{K}^{+}$channel blocker) had no effects, suggesting that the relaxant response of oligopeptides was involved in the role of $\mathrm{K}^{+}$channel opening of $\mathrm{Ca}^{2+}$-activated $\mathrm{K}^{+}$channel in vascular smooth muscle cells. Influx of extracellular $\mathrm{Ca}^{2+}$ through voltage and/or receptor-operated calcium channels (VOCCs and/or ROCCs) plays an important role in vascular smooth muscle contraction. We note that oligopeptides induced vasorelaxation in aortic rings precontracted with $\mathrm{KCl}$ or phenylephrine. From this result, it can be concluded that oligopeptides induced vasorelaxation via different pathways. It is well known that $\mathrm{KCl}$ induces smooth muscle contraction through the activation of voltage-dependent calcium channels and subsequent release of calcium from sarcoplasmic reticulum, whereas phenylephrine-induced vasoconstriction is mediated by the stimulation of G-proteins coupled to alpha-adrenoceptors. We then investigated the mechanism for the vasodilator action of oligopeptides that could directly inhibit the $\mathrm{Ca}^{2+}$ influx in the vascular smooth muscle cells. Oligopeptides significantly reduced the contractile response induced by $\mathrm{CaCl}_{2}$ in the endothelium-denuded ring, in concentration-dependent manner under a depolarizing solution. The contraction was abolished by nifedipine, a typical L-type voltage-operated calcium channel blocker, confirming the involvement of L-type voltage-operated calcium channels in the contractile response. The concentration-response curve of $\mathrm{CaCl}_{2}$ decreased in $E_{\max }$, while the $\mathrm{EC}_{50}$ values were unchanged, suggesting that oligopeptides could act as a calcium channel blocker that interferes with $\mathrm{Ca}^{2+}$ influx through L-type $\mathrm{Ca}^{2+}$ channel of aorta smooth muscle membrane [25]. The influences of oligopeptides in $\mathrm{Ca}^{2+}$ released from intracellular stores were sensitive to phenylephrine, and caffeine was also determined. The oligopeptides markedly decreased the contractions induced by phenylephrine, which stimulates $\mathrm{IP}_{3}$-dependent $\mathrm{Ca}^{2+}$ release from the intracellular store [26]. By contrast, caffeine-induced contractions, which release $\mathrm{Ca}^{2+}$ from intracellular stores by $\mathrm{IP}_{3}$-independence, were not altered. Thus, it seems likely that the vascular effects of oligopeptides involved a reduction of $\mathrm{IP}_{3}$-dependent $\mathrm{Ca}^{2+}$ releases form SR sensitive to phenylephrine $[27,28]$.

Our results demonstrated that bioactive oligopeptides $(\leq 5 \mathrm{kDa})$ fractions obtained from silk sericin lower blood pressure by a direct effect on both endothelium and vascular smooth muscle leading to vasodilation. Results from this study have also supported us to further identify and characterize bioactive peptides.

\section{Conclusions}

This study demonstrated the hypotensive effect and vasorelaxant effect of silk sericin-derived oligopeptides on isolated rat aorta and the possible mechanisms. The results suggested that oligopeptides have a dose-dependent relaxing effect on the isolated rat aorta. The relaxing effect of oligopeptides is mediated through $\mathrm{Ca}^{2+}$ antagonism and the NO/sGC/cGMP pathway, which possibly explains the fall in BP. These findings provide scientific evidence supporting the therapeutic uses of sericin-derived oligopeptides as vascular modulators.

\section{Conflict of Interests}

The authors have declared no conflict of interests.

\section{Acknowledgment}

This work was supported by the Agricultural Research Development Agency (public organization), Thailand.

\section{References}

[1] F. Hong, L. Ming, S. Yi, L. Zhanxia, W. Yongquan, and L. Chi, "The antihypertensive effect of peptides: a novel alternative to drugs?” Peptides, vol. 29, no. 6, pp. 1062-1071, 2008. 
[2] H. Yoshii, N. Tachi, R. Ohba, O. Sakamura, H. Takeyama, and T. Itani, "Antihypertensive effect of ACE inhibitory oligopeptides from chicken egg yolks," Comparative Biochemistry and Physiology C, vol. 128, no. 1, pp. 27-33, 2001.

[3] P. Ruiz-Giménez, J. B. Salom, J. F. Marcos et al., "Antihypertensive effect of a bovine lactoferrin pepsin hydrolysate: identification of novel active peptides," Food Chemistry, vol. 131, no. 1, pp. 266-273, 2012.

[4] M. Miguel, M. J. Alonso, M. Salaices, A. Aleixandre, and R. López-Fandiño, "Antihypertensive, ACE-inhibitory and vasodilator properties of an egg white hydrolysate: effect of a simulated intestinal digestion," Food Chemistry, vol. 104, no. 1, pp. 163-168, 2007.

[5] H.-Y. Yang, S.-C. Yang, S.-T. Chen, and J.-R. Chen, "Soy protein hydrolysate ameliorates cardiovascular remodeling in rats with 1-NAME-induced hypertension," The Journal of Nutritional Biochemistry, vol. 19, no. 12, pp. 833-839, 2008.

[6] D. Sánchez, M. Kassan, M. D. M. Contreras et al., "Long-term intake of a milk casein hydrolysate attenuates the development of hypertension and involves cardiovascular benefits," Pharmacological Research, vol. 63, no. 5, pp. 398-404, 2011.

[7] K. Ishiguro, Y. Sameshima, T. Kume, K.-I. Ikeda, J. Matsumoto, and M. Yoshimoto, "Hypotensive effect of a sweetpotato protein digest in spontaneously hypertensive rats and purification of angiotensin I-converting enzyme inhibitory peptides," Food Chemistry, vol. 131, no. 3, pp. 774-779, 2012.

[8] M. Miguel, Y. Alvarez, R. López-Fandiño, M. J. Alonso, and M. Salaices, "Vasodilator effects of peptides derived from egg white proteins," Regulatory Peptides, vol. 140, no. 3, pp. 131-135, 2007.

[9] R. Ringseis, B. Matthes, V. Lehmann et al., "Peptides and hydrolysates from casein and soy protein modulate the release of vasoactive substances from human aortic endothelial cells," Biochimica et Biophysica Acta, vol. 1721, pp. 89-97, 2005.

[10] M. Miguel, M. A. Manso, R. López-Fandiño, M. J. Alonso, and M. Salaices, "Vascular effects and antihypertensive properties of $\kappa$-casein macropeptide," International Dairy Journal, vol. 17, no. 12, pp. 1473-1477, 2007.

[11] W. Yuan, J. Wang, and F. Zhou, "In vivo hypotensive and physiological effects of a silk fibroin hydrolysate on spontaneously hypertensive rats," Bioscience, Biotechnology, and Biochemistry, vol. 76, pp. 1987-1989, 2012.

[12] F. Zhou, Z. Xue, and J. Wang, "Antihypertensive effects of silk fibroin hydrolysate by alcalase and purification of an ACE inhibitory dipeptide," Journal of Agricultural and Food Chemistry, vol. 58, no. 11, pp. 6735-6740, 2010.

[13] Y. Takasu, H. Yamada, and K. Tsubouchi, "Isolation of three main sericin components from the cocoon of the silkworm, Bombyx mori," Bioscience, Biotechnology and Biochemistry, vol. 66, no. 12, pp. 2715-2718, 2002.

[14] Y.-G. Li, D.-F. Ji, T.-B. Lin, S. Zhong, G.-Y. Hu, and S. Chen, "Protective effect of sericin peptide against alcohol-induced gastric injury in mice," Chinese Medical Journal, vol. 121, no. 20, pp. 2083-2087, 2008.

[15] S. Zhaorigetu, M. Sasaki, H. Watanabe, and N. Kato, "Supplemental silk protein, sericin, suppresses colon tumorigenesis in 1,2-dimethylhydrazine-treated mice by reducing oxidative stress and cell proliferation," Bioscience, Biotechnology and Biochemistry, vol. 65, no. 10, pp. 2181-2186, 2001.

[16] W. Kaewkorn, N. Limpeanchob, W. Tiyaboonchai, S. Pongcharoen, and M. Sutheerawattananonda, "Effects of silk sericin on the proliferation and apoptosis of colon cancer cells," Biological Research, vol. 45, pp. 45-50, 2012.
[17] N. Limpeanchob, K. Trisat, A. Duangjai, W. Tiyaboonchai, S. Pongcharoen, and M. Sutheerawattananonda, "Sericin reduces serum cholesterol in rats and cholesterol uptake into Caco-2 cells," Journal of Agricultural and Food Chemistry, vol. 58, no. 23, pp. 12519-12522, 2010.

[18] S. I. H. Taqvi, A. J. Shah, and A. H. Gilani, "Blood pressure lowering and vasomodulator effects of piperine," Journal of Cardiovascular Pharmacology, vol. 52, no. 5, pp. 452-458, 2008.

[19] S. N. Jin, J. F. Wen, X. Li, D. G. Kang, H. S. Lee, and K. W. Cho, "The mechanism of vasorelaxation induced by ethanol extract of Sophora flavescens in rat aorta," Journal of Ethnopharmacology, vol. 137, no. 1, pp. 547-552, 2011.

[20] N. Kato, S. Sato, A. Yamanaka, H. Yamada, N. Fuwa, and M. Nomura, "Silk protein, sericin, inhibits lipid peroxidation and tyrosinase activity," Bioscience, Biotechnology, and Biochemistry, vol. 62, no. 1, pp. 145-147, 1998.

[21] Y.-G. Li, D.-F. Ji, S. Chen, and G.-Y. Hu, "Protective effects of sericin protein on alcohol-mediated liver damage in mice," Alcohol and Alcoholism, vol. 43, no. 3, pp. 246-253, 2008.

[22] R. Dash, M. Mandal, S. K. Ghosh, and S. C. Kundu, "Silk sericin protein of tropical tasar silkworm inhibits UVB-induced apoptosis in human skin keratinocytes," Molecular and Cellular Biochemistry, vol. 311, no. 1-2, pp. 111-119, 2008.

[23] O. Hernández-Abreu, P. Castillo-España, I. León-Rivera et al., "Antihypertensive and vasorelaxant effects of tilianin isolated from Agastache mexicana are mediated by NO/cGMP pathway and potassium channel opening," Biochemical Pharmacology, vol. 78, no. 1, pp. 54-61, 2009.

[24] R. D. C. V. D. A. F. da Silva, S. Crestani, P. de Souza et al., "Endothelium-dependent and independent vasorelaxation induced by an n-butanolic fraction of bark of Scutia buxifolia Reiss (Rhamanaceae)," Journal of Ethnopharmacology, vol. 141, pp. 997-1004, 2012.

[25] X.-L. Wu, Y.-Y. Wang, J. Cheng, and Y.-Y. Zhao, "Calcium channel blocking activity of calycosin, a major active component of Astragali Radix, on rat aorta," Acta Pharmacologica Sinica, vol. 27, no. 8, pp. 1007-1012, 2006.

[26] A. M. Gurney and M. Allam, "Inhibition of calcium release from the sarcoplasmic reticulum of rabbit aorta by hydralazine," British Journal of Pharmacology, vol. 114, no. 1, pp. 238-244, 1995.

[27] G.-J. Chang, T.-P. Lin, Y.-S. Ko, and M.-S. Lin, "Endotheliumdependent and -independent vasorelaxation induced by CIJ-3$2 \mathrm{~F}$, a novel benzyl-furoquinoline with antiarrhythmic action, in rat aorta," Life Sciences, vol. 86, no. 23-24, pp. 869-879, 2010.

[28] O. A. Adaramoye, R. M. Anjos, M. M. Almeida et al., "Hypotensive and endothelium-independent vasorelaxant effects of methanolic extract from Curcuma longa L. in rats," Journal of Ethnopharmacology, vol. 124, no. 3, pp. 457-462, 2009. 

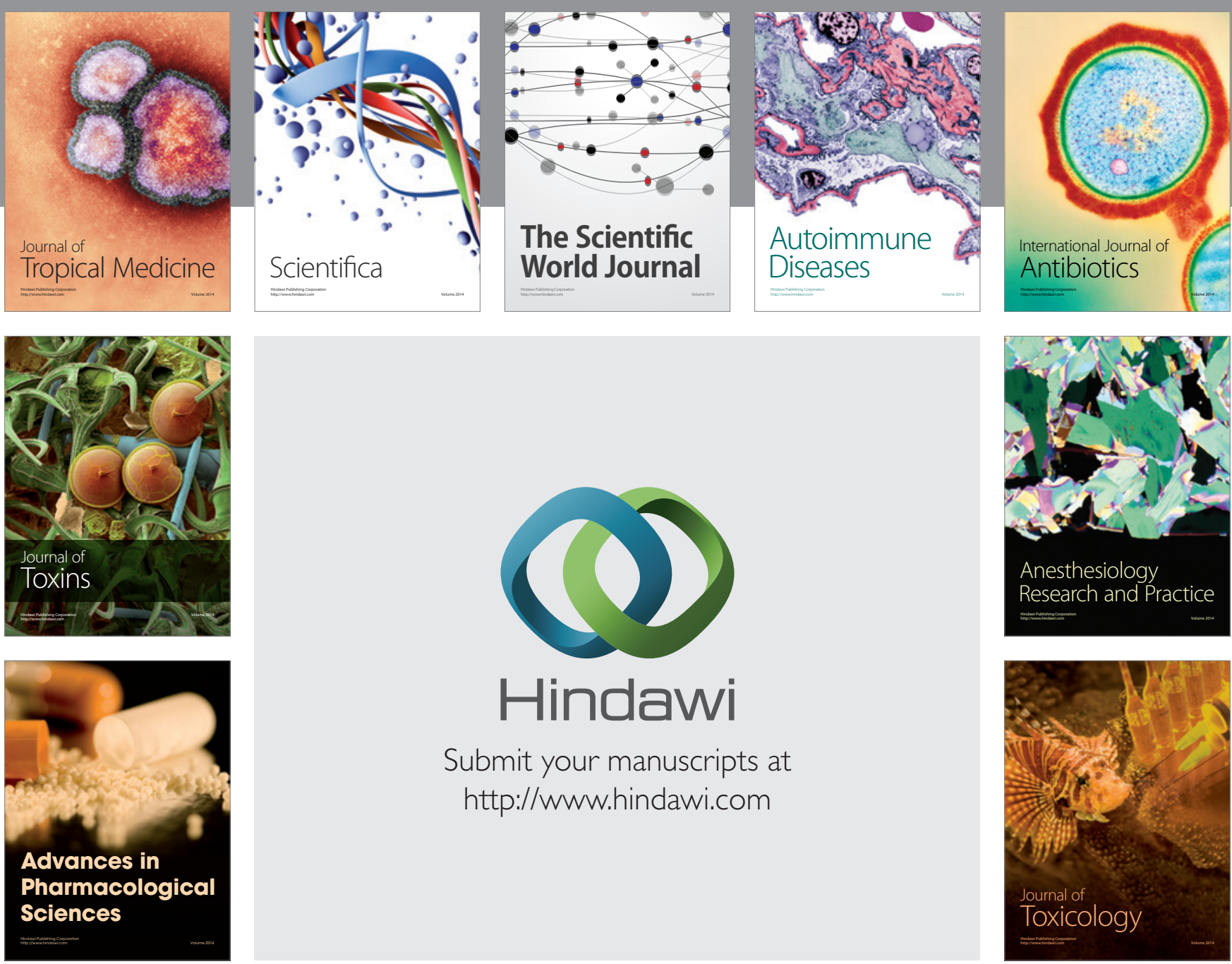

\section{Hindawi}

Submit your manuscripts at

http://www.hindawi.com
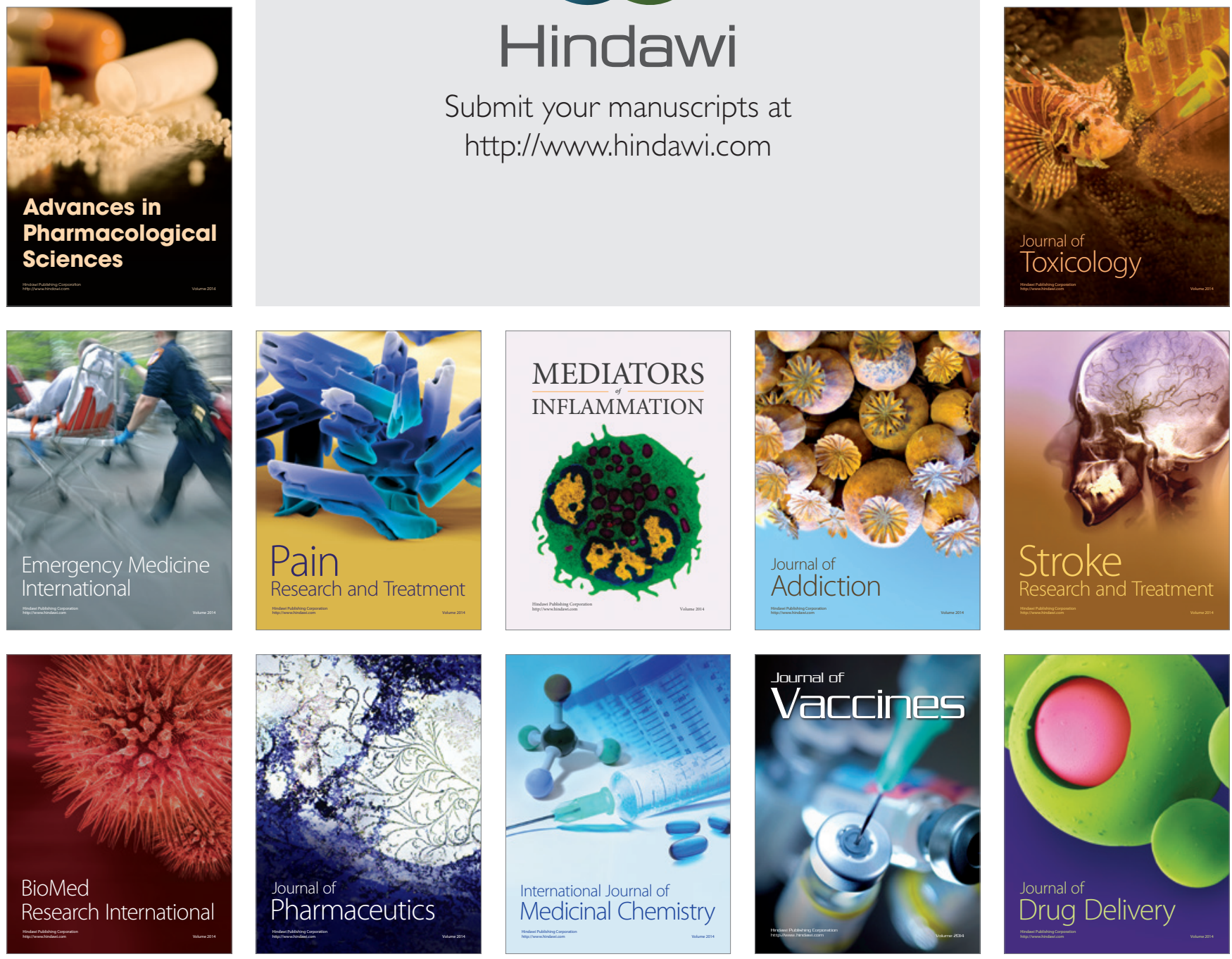